\title{
A IMAGEM DA CIÊNCIA E AS IMAGENS VISUAIS NA FORMAÇÃO SUPERIOR E AS PESQUISAS SOBRE O ENSINO DE FÍSICA*
}

\author{
Sheila Cristina Ribeiro Rego*
}

\begin{abstract}
RESUMO: Nesse estudo apresentamos, primeiramente, aspectos dos processos de mudança de paradigma que ocorrem nas ciências naturais e suas influências nos manuais didáticos (KUHN, 2005). Em seguida, expomos resultados de um levantamento acerca de pesquisas que abordam imagens fixas no ensino de Física, buscando compreender o que tem sido considerado importante em seu uso, em especial, nos livros didáticos. Dos artigos analisados pelo presente trabalho, percebemos uma carência na discussão sobre os paradigmas da ciência transmitidos por meio de imagens em livros didáticos de Física. Pensamos ser essa uma reflexão importante, uma vez que trata da visão de mundo da ciência com que estudantes entram em contato em sua formação acadêmica e que, de alguma forma, influenciará sua atuação na vida.
\end{abstract}

Palavras-chave: Imagem. Livro didático. Física. Paradigma.

* Tanto a reflexão teórica quanto os resultados apresentados aqui fazem parte da tese de doutorado da autora (REGO, 2011).

** Programa de Pós-Graduação em Ensino de Ciências e Matemática do Centro Federal de Educação Tecnológica do Rio de Janeiro (Cefet). Rio de Janeiro (RJ) - Brasil.

Contato com a autora: <scrrego@gmail.com>

Cad. Cedes, Campinas, v. 34, n. 92, p. 69-85, jan.-abr. 2014

Disponível em <http://www.cedes.unicamp.br> 
A imagem da ciência e as imagens visuais na formação superior...

\title{
THE IMAGE OF SCIENCE AND VISUAL IMAgES IN HIGHER EDUCATION AND RESEARCH ON PHYSICS TEACHING
}

\begin{abstract}
In this study we present, firstly, aspects of the processes of paradigm change that occur in the natural sciences and their influence in textbooks (KUHN, 2005). Next, we expose results of a survey concerning research that approaches fixed images in Physics teaching, searching to understand what has been considered as important in its use, especially in textbooks. As from the articles analyzed by the present work, we notice a lack of discussion on the paradigms of science transmitted through images in Physics textbooks. We highlight the importance of this reflection, because it deals with the world view of science with which students get in touch in their academic life and that, somehow, will influence their performance in life.
\end{abstract}

Key words: Image. Textbook. Physics. Paradigm.

\section{Introdução}

$\mathrm{K}$

uhn (2005), ao tratar do progresso das ciências naturais, dividiu o trabalho científico em ciência normal e ciência extraordinária. didáticos, constitui a formação dos cientistas e é predominante em sua atuação profissional. A última surge apenas quando a ciência sofre uma mudança de paradigma, isto é, quando ocorre uma revolução científica. Kuhn (op. cit., p. 13) entende por paradigmas "as realizações científicas universalmente reconhecidas que, durante algum tempo, fornecem problemas e soluçôes modulares para uma comunidade de praticantes de uma ciência”.

Uma das fontes de transmissão dos paradigmas vigentes às novas gerações de profissionais é o livro didático. Nele, os estudantes entram em contato com uma visão de mundo, uma forma de pensar e de avaliar o que é importante em sua época, por meio da leitura de textos verbais e imagéticos.

Atualmente, a avaliação dos livros didáticos de Física para o ensino médio leva em conta a utilização das imagens e sua relação com o texto verbal (BRASIL, 2011), mostrando a necessidade e/ou importância atribuída à imagem no processo educacional. Algumas pesquisas desenvolvidas no âmbito da Educação em Ciências demonstraram dificuldades relacionadas à produção e à leitura das imagens presentes em materiais didáticos de 
Física, como, por exemplo, uma tendência de assumi-las como evidentes e transparentes, não necessitando de interpretação para sua compreensão (OTERO; MOREIRA; GRECA, 2002) ao invés de admiti-las como objetos simbólicos "produzidos histórico-socialmente como parte da cultura humana” (SILVA, 2006, p. 72).

Nesse estudo apresentamos, primeiramente, aspectos dos processos de mudança de paradigma que ocorrem nas ciências naturais e suas influências nos manuais didáticos (KUHN, 2005). Em seguida, expomos resultados de um levantamento acerca de pesquisas que abordam imagens fixas no ensino de Física, buscando compreender o que tem sido considerado importante em seu uso, em especial, nos livros didáticos.

Imagem da ciência e imagens visuais na formação superior

A ciência normal tem como fundamento realizações científicas do passado. Assim, o trabalho do cientista é baseado em conceitos estabelecidos por estudiosos anteriores. Esses conceitos orientam a visão de mundo do cientista, conduzindo-o a perguntas sobre esse mundo que podem levá-lo a medições, tendo em vista o refinamento da teoria aceita pela comunidade científica. Sua preocupação, geralmente, não é descobrir novos conceitos ou formular uma nova teoria, mas ajustar a natureza aos conceitos e teorias reconhecidos (KUHN, op. cit.).

Para o bem do progresso da ciência, de vez em quando, durante o processo da ciência normal, acontece algo não programado pela teoria do paradigma: surge uma anomalia, que, como tal, não era prevista pela teoria e, portanto, não era imaginada pelo cientista e com a qual ele não foi preparado para lidar. $O$ fracasso da teoria em explicar uma anomalia leva cientistas a uma crise que pode culminar em três efeitos. A primeira atitude da comunidade científica é tentar, de várias maneiras, fazer com que a anomalia se adapte ao paradigma, ou seja, realizar a tarefa da ciência normal. Algumas vezes, a ciência normal consegue resolver o problema. Quando isso não acontece, faz-se necessário pensar em novas abordagens. Se a anomalia resistir a essas abordagens, pode-se, momentaneamente, abrir mão de sua solução, admitindo-se que não se tem conhecimento suficiente para explicá-la. Em outros casos, responsáveis pelas revoluções científicas, a crise pode dar origem a um novo candidato a paradigma, que se mostra capaz de solucionar a anomalia, e alguns lutarão por sua aceitação.

Cad. Cedes, Campinas, v. 34, n. 92, p. 69-85, jan.-abr. 2014 
A imagem da ciência e as imagens visuais na formação superior...

A ciência nunca abandona um paradigma se não houver outro para substituí-lo. A essa transição para um novo paradigma, Kuhn (2005) denomina revolução científica, que caracteriza a ciência extraordinária. Revoluções científicas, em geral, são associadas às pessoas que as viveram ou que desenvolveram teorias e/ou medições que foram utilizadas para defendê-las ou opor-se a elas. Assim, podemos citar a astronomia copernicana contra a ptolomaica, a teoria de Lavoisier sobre a combustão do oxigênio e a mudança de visão da dinâmica aristotélica para a galileana.

A elaboração e a aceitação de um novo paradigma não ocorrem de forma instantânea e passiva pela comunidade científica, e a anomalia incide sobre os fundamentos de seus conhecimentos. A crise que acompanha o aparecimento da anomalia se deve ao questionamento das bases do trabalho de um campo de estudos, as crenças de um grupo de profissionais, os métodos utilizados durante anos de pesquisas e a visão de mundo que norteou as perguntas sobre a natureza. Por tocar em pontos tão importantes, a transição entre paradigmas vem acompanhada por resistências da parte de estudiosos da área abalada pela anomalia, uma vez que novos conhecimentos não surgem para ocupar o lugar da ignorância, mas para substituir outros conhecimentos.

Após a aceitação do novo paradigma, ele começa a direcionar a pesquisa da ciência normal e a formação de novos profissionais, incluindo-se os livros didáticos que "são produzidos somente a partir dos resultados de uma revolução científica. Eles servem de base para uma nova tradição de ciência normal" (KUHN, op. cit., p. 185).

Ao renunciar a um paradigma, a comunidade científica parece excluir da formação dos novos cientistas livros e artigos baseados no mesmo. Os estudantes, iniciados na ciência em um novo paradigma, dificilmente terão contato com o anterior. Quando esse contato ocorre, a visão que terão do passado é como um processo de acumulação, como se o paradigma atualmente aceito e, consequentemente, as teorias que abarca tivessem sido originadas a partir do paradigma anterior e não como uma disputa entre paradigmas ocasionada por uma revolução (KUHN, 2005).

A imagem de ciência como um processo de adiçôes de conhecimentos se deve, principalmente, aos livros didáticos por se referirem "a um corpo já articulado de problemas, dados e teorias, e muito frequentemente ao conjunto particular de paradigmas aceitos pela comunidade científica da época em que esses textos foram escritos" (ibid., p. 176). Ao negligenciar 
ou distorcer a história da ciência, o progresso da ciência parece ser um acontecimento cumulativo. Os livros didáticos relatam, quase que exclusivamente, a atividade da ciência normal, não tratando da transição presente na ciência extraordinária.

Talvez influenciada, entre outros aspectos, pelos livros didáticos, a maioria dos estudantes de ciência compartilhe da opinião dos leigos de que o estado atual de desenvolvimento científico só foi possível graças a esforços individuais de pessoas com capacidade intelectual sobre-humana e dedicação sacerdotal à ciência, que foram juntando, sequencialmente, fatos, ideias, definiçōes, leis ou teorias para formarem o conjunto de informaçōes apresentadas pelos livros didáticos. Além disso, parece que as descobertas presentes nesses materiais já faziam parte dos objetivos iniciais dos que trabalharam em seu processo de surgimento, sendo apenas consequências de investigações direcionadas para tal e não como resultado de algo que elas não previam.

Os manuais didáticos formam gerações de profissionais. Embora, ao longo do tempo, eles sofram mudanças devido ao desenvolvimento de novas técnicas de impressão e à demanda por uma organização visual adaptada às formas de leitura contemporâneas, sua organização, conteúdo, exemplos, exercícios e, consequentemente, sua visão de ciência, geralmente, permanecem os mesmos. Diferentemente dos livros didáticos de Ciências (para o ensino fundamental) e de Física (para o ensino médio), que experimentam alterações significativas por conta da demanda surgida a partir de pesquisas na área da Educação, da prática educacional e de políticas públicas, verificamos poucas alterações nos livros didáticos destinados ao nível superior. Os utilizados na educação básica têm passado por modificações ao incorporarem contribuições da Filosofia e da História da Ciência, das teorias da cognição, do movimento de Ciência, Tecnologia e Sociedade (CTS), da abordagem sociológica da escola, dos estudos da cultura e da valorização das atividades de experimentação, entre outros (GOUVÊA; OLIVEIRA, 2010).

Segundo Kuhn (2005), na formação acadêmica nas áreas das artes gráficas, literatura e música, os manuais possuem um papel secundário, pois ela se baseia na exposição dos estudantes às obras de outros profissionais, especialmente as que não lhe são contemporâneas. Nas ciências sociais, os estudantes têm a possibilidade de pensar em problemas que não possuem uma única resposta (como os enfrentados pela educação brasileira); eles entram em contato com diferentes opiniōes sobre as causas e possíveis 
A imagem da ciência e as imagens visuais na formação superior...

soluções para esses problemas através de pesquisas recentes e de aspectos históricos envolvendo os mesmos. Os manuais têm um papel importante em sua formação, mas não são fonte de informação exclusiva. Nas ciências naturais atuais, até que o estudante comece sua própria pesquisa, sua vida acadêmica se fundamenta nos manuais didáticos: ele não tem contato com resultados de pesquisas recentes, nem com o desenvolvimento do pensamento que originou as ideias presentes nos manuais.

Ao iniciar-se em uma comunidade científica, o estudante passa a partilhar de sua "matriz disciplinar", composta pelos paradigmas aceitos pela comunidade, que podem ser expressos, entre outros, pelos "exemplares", que possuem, talvez, o papel mais importante no aprendizado de uma ciência. Presentes nos livros didáticos, trata-se de "soluções concretas de problemas que os estudantes encontram desde o início de sua educação científica, seja nos laboratórios, exames ou no fim dos capítulos dos manuais científicos" e em publicações periódicas (KUHN, op. cit., p. 234). Qual estudante de Física não resolveu problemas de roldanas, planos inclinados, movimento de satélites, alavancas, pêndulos, associação de resistores e calorímetros? Não basta ser colocado em contato com as generalizações simbólicas da ciência para se entender os conceitos presentes em um modelo científico: a resolução de problemas se faz necessária para o aprendizado desses conceitos. O estudante "absorve" uma maneira de ver que o ajuda a compreender semelhanças entre os problemas, a determinar relações entre os símbolos e a empregá-los em outras situaçôes. "As aplicações não estão lá simplesmente como um adorno ou mesmo como documentação. Ao contrário, o processo de aprendizado de uma teoria depende do estudo das aplicaçôes, incluindo-se aí a prática na resolução de problemas" (ibid., p. 71).

Os “exemplares", geralmente, apresentam imagens visuais que também fazem parte da formação do estudante. $\mathrm{O}$ seu aprendizado inclui a leitura dessas imagens, que se torna recorrente e padronizada.

A Figura 1 apresenta imagens com as quais os estudantes de Física são familiarizados: elas tratam, respectivamente, de situações referentes ao estudo do movimento de uma partícula (A), de circuitos elétricos (B), do equilíbrio do corpo rígido (C) e da segunda lei de Newton (D). Para compreendê-las, o estudante precisa passar por uma transformação de visão que acompanha a aceitação de um paradigma. "O que um homem vê depende tanto daquilo que ele olha como daquilo que sua experiência visual-conceitual prévia o ensinou a ver" (KUHN, 2005, p. 150). Ao expor essas imagens para uma 
criança de 5 anos e para um licenciando em Física, ambos estarão em contato com os mesmo estímulos visuais, mas terão sensações diferentes.

\section{Figura 1}

Imagens recorrentes no ensino de Física

A)

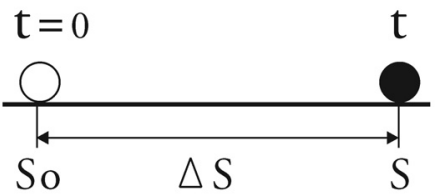

Fonte: REGO, S.C.R. [sem título]. 2011. Desenho. Fonte: REGO, S.C.R. [sem título]. 2011. Desenho. Arquivo pessoal.

C)

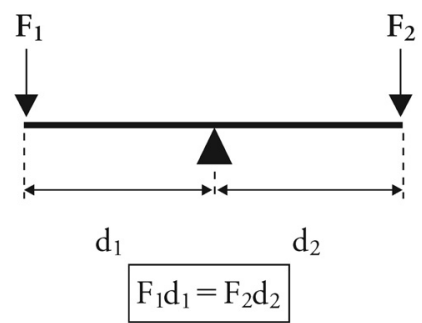

Fonte: REGO, S.C.R. [sem título]. 2011. Desenho. Fonte: ALMEIDA, M.A.T. Maçã no piso de um Arquivo pessoal.

É de se esperar que profissionais com formações acadêmicas na mesma área do conhecimento compartilhem da mesma leitura de imagens provenientes dessa área. Por seu contato exaustivo com determinadas imagens, principalmente através dos "exemplares", eles devem reconhecer os 
A imagem da ciência e as imagens visuais na formação superior...

elementos que a compóem e compreender seus sentidos, conduzidos por um paradigma, mesmo sem terem passado por um processo direcionado conscientemente à alfabetização para sua leitura.

Procurando refletir sobre aspectos da utilização da imagem visual fixa no ensino de Física, expomos, a seguir, elementos que têm sido considerados relevantes em algumas pesquisas que abordaram esse tema, detendo-nos um pouco mais sobre aquelas que fizeram uso do livro didático.

\section{A imagem em pesquisas sobre o ensino de Física}

Com o objetivo de compreender como a imagem fixa é tratada nas pesquisas que vêm sendo desenvolvidas, realizamos um levantamento dos periódicos classificados como A1 e A2 (que se referem às produções de nível mais elevado) pela Coordenação de Aperfeiçoamento de Pessoal de Nível Superior (Capes) na área de Educação, disponibilizados pelo Qualis ${ }^{1}$ em agosto de 2009. Limitamo-nos a examinar os trabalhos que abordavam as imagens fixas por serem, historicamente, as primeiras a surgirem e por continuarem fortemente presentes em atividades de ensino, sendo visualizadas por meio do quadro-negro, folhas de caderno, livros, revistas, jornais, entre outros.

Foram consultados 130 periódicos, no período de 1998 a 2007, nos quais encontramos 14 artigos que tratavam de reflexões sobre a imagem no ensino de Física. Para selecionarmos os artigos que abordavam a imagem fixa, examinamos seus títulos na busca de palavras (imagem, ilustração, gráfico, desenho, entre outros) que nos indicassem relevância para o estudo.

As imagens utilizadas em livros didáticos foram o tema de cinco artigos, sendo quatro referentes a livros do ensino médio e um tratando dos níveis médio e superior. Os demais tratavam de temas variados, conforme mostramos a seguir.

Por meio de um teste de múltipla escolha, Agrello e Garg (1999) examinaram a leitura de gráficos de cinemática realizada por calouros de cursos de Engenharia, Ciência da Computação, Física, Geologia, Matemática e Química da Universidade de Brasília (UnB), com a finalidade de, a partir de suas respostas, identificarem suas dificuldades na leitura de gráficos e, de posse dessas informaçôes, ajudá-los em seu aprendizado na disciplina de Física 1. 
Utilizando imagens provenientes, basicamente, da internet, Peduzzi (1999) complementou o material didático de uma disciplina do curso de Física da Universidade Federal de Santa Catarina (UFSC), apresentando algumas vantagens de seu uso no ensino da mecânica.

Otero, Greca e Silveira (2003), baseando-se no campo de estudos da cognição, investigaram influências que atividades de ensino fundamentadas no uso de imagens pudessem ter no rendimento escolar de estudantes do ensino médio. Para isso, trabalharam com o tema "Oscilações livres, forçadas e amortecidas e suas aplicações" em aulas de dois grupos de estudantes: em um dos grupos foram desenvolvidas atividades onde a imagem era utilizada abundantemente, enquanto, no outro, o estudo foi ministrado de forma "tradicional". O rendimento dos grupos foi verificado com pré e pós-testes, por meio de análises estatísticas de suas respostas. De acordo com os autores, não houve diferenças significativas nas médias de pontos dos dois grupos.

Um projeto em que estudantes criaram "tirinhas", onde expuseram corretamente ideias ou princípios científicos, foi descrito por GonzálezEspada (2003), com o objetivo de familiarizar professores, principalmente de Física, com a utilização de cartuns e tirinhas como meios de facilitar o aprendizado.

Para investigar as ideias acerca das imagens como recurso pedagógico, baseando-se num referencial do campo de estudos da cognição, Fanaro, Otero e Greca (2005) elaboraram um questionário, a partir da análise de livros didáticos de Física, que foi aplicado a professores dos níveis médio e superior. Seus resultados indicaram que um número considerável de professores compartilhava da crença sobre as vantagens e benefícios do uso das imagens visuais no aprendizado para diminuir a abstração dos conhecimentos científicos, facilitar sua compreensão, aproximá-los do cotidiano do estudante, entre outros.

Costa e Almeida (2005) discutiram características da formação de imagens tridimensionais em espelhos e lentes, assunto, geralmente, negligenciado pelos livros didáticos e nos cursos de licenciatura em Física.

Um modelo computacional de analogia visual para a resolução de problemas foi descrito por Davies, Nersessian e Goel (2005), exemplificando-se sua utilização para representar um pouco do raciocínio de Maxwell sobre o eletromagnetismo. 
Galili e Zinn (2007) sugeriram a inclusão de exemplos de obras de arte no currículo de ciências para a compreensão de alguns conceitos de óptica, através da discussão de seus contextos de criação. Os autores apresentaram a ciência e a arte como duas formas de denotar a natureza: a primeira fornecendo um conhecimento objetivo (na medida em que tenta controlar a polissemia) e a segunda um conhecimento subjetivo.

Imagens selecionadas de livros didáticos de Física do nível universitário foram utilizadas por Aguilar, Maturano e Núñez (2007) em duas provas (pré e pós-testes) para pesquisar concepções alternativas de estudantes dos cursos de Astronomia e Geofísica sobre movimento.

\section{Imagens em livros didáticos}

Como mencionado anteriormente, do levantamento realizado foram encontrados cinco artigos que possuíam como tema as imagens nos livros didáticos.

Jiménez Valladares e Perales Palacios (2001) tomaram como objeto de estudo o livro didático de Física e Química do nível secundário. Seu interesse foi justificado por considerarem o livro didático como o meio mais utilizado e aceito pela comunidade educativa para a transmissão da ciência escolar. Seu objetivo foi

[...] desenvolver um instrumento de análise das sequências didáticas de livros didáticos de ciências que possibilite, por um lado, determinar o papel que os autores atribuem às ilustraçôes e, por outro, dispor de um sistema de indicadores relativos à metodologia de ensino subjacente a cada livro. ${ }^{2}$ (JIMÉNEZ VALLADARES; PERALES PALACIOS, op. cit., p. 4; tradução nossa)

A análise foi focalizada na estrutura sintática (sequência dos conteúdos) e curricular (metodologia didática subtendida), e consistiu em dividir o texto em unidades e classificá-las de acordo com a sua função, segundo categorias empíricas (evocação, definição, aplicação, descrição, interpretação e problematização), tendo em vista compreender quais eram os princípios que orientavam a posição espacial e o papel das imagens no livro. Foram examinados os temas de estática e dinâmica em dez livros. Entre suas conclusōes, os autores identificaram uma maior utilização de imagens em situaçôes para exemplificar e definir conceitos e delinear problemas. Além 
disso, perceberam uma tendência de mudanças significativas na estrutura dos livros que demandavam novas formas de análise.

Utilizando as imagens desses livros, Jiménez Valladares e Perales Palacios (2002a) discutiram alguns exemplos de imagens empregadas de forma inconveniente como argumento visual para convencer os leitores da veracidade dos conceitos trabalhados por eles. As imagens eram usadas como evidências experimentais, do que, geralmente, são interpretações fundamentadas na teoria científica que se deseja demonstrar.

Com a mesma amostra de livros e o mesmo conteúdo didático, os autores aplicaram uma taxonomia para a categorização de ilustraçōes (JIMÉNEZ VALLADARES; PERALES PALACIOS, 2002b). Antes de propor essa taxonomia e uma metodologia de análise das imagens, eles apresentaram a fundamentação teórica em que se basearam para avaliar a adequação das imagens nos livros. Essa fundamentação se refere a algumas contribuições do campo de estudos da Psicologia e a investigações empíricas anteriores. As categorias de análise foram: função da sequência didática em que a aparece a ilustração, nível de iconicidade, funcionalidade das imagens, relação com o texto principal, texto verbal dentro das ilustraçōes e conteúdo científico que as sustentava. Os autores encontraram várias deficiências e incoerências nas ilustraçōes, a falta de texto verbal nas mesmas e uma fraca relação entre elas e o texto principal.

A relação de iconicidade (nível de semelhança com a realidade) entre as representaçōes visuais em livros didáticos de Física e as ideias que elas têm a intenção de comunicar foi investigada por Medeiros e Medeiros (2001). Seu problema de pesquisa foi "até que ponto tais representaçōes efetivamente guardam semelhanças com os objetos epistemológicos da Física ou apenas com os objetos da realidade concreta" (p. 104). A título de exemplos, eles examinaram três imagens de livros didáticos para o ensino médio. Essa análise indicou que as imagens apresentavam diferenças profundas em relação à realidade pensada (os modelos construídos pela ciência para a compreensão da natureza), embora fossem muito semelhantes à realidade concreta (cotidiana), podendo acarretar uma confusão entre essas realidades.

O único artigo que tratava do uso de imagens em livros didáticos de Física no ensino superior, juntamente com livros do nível médio, se fundamentou no campo de estudos da cognição para investigar "a influência que determinadas representaçōes externas proporcionadas ao sujeito poderiam ter nas representaçōes mentais que constrói sobre um fenômeno físico"3 
A imagem da ciência e as imagens visuais na formação superior...

(OTERO; MOREIRA; GRECA, 2002, p. 128; tradução nossa). Foram examinados 41 livros, sendo dez universitários. As categorias sobre as quais se baseou o exame dos textos surgiram a partir do trabalho empírico sobre os mesmos e seu tratamento se deu numa análise estatística. Essas categorias foram: características gerais da imagem, relação entre imagem e texto verbal e características do livro didático.

Os autores verificaram que as características das imagens e sua relação com o texto verbal estavam significativamente associadas ao nível educativo do livro, que parecia orientar o uso de recursos visuais, o estilo de comunicação e o tipo de notações privilegiadas. Além disso, não detectaram a influência dos resultados de pesquisas atuais sobre a utilização das imagens visuais no campo da cognição. No que se refere à relação entre texto e imagem, esta apareceu em duas formas básicas: descritiva (trinta livros) e associativa (nove livros). No primeiro caso, as imagens são descritas e explicadas pelo texto verbal e, no segundo, há poucas referências às imagens no texto. Somente dois livros apresentaram uma relação entre texto-imagem claramente interativa, isto é, a imagem era empregada como fonte de informação para gerar conhecimento.

\section{Resultados encontrados}

É importante ressaltar que esse levantamento não contemplou produções apresentadas em eventos e em trabalhos de final de curso (graduação, especialização, mestrado e doutorado) no período considerado. Contudo, parece que, através dele, podemos ter uma visão geral das pesquisas desenvolvidas acerca do uso da imagem no ensino de Física, no período considerado, uma vez que a maioria das produçóes de fim de curso acaba sendo, em parte, publicada em forma de artigos.

A imagem foi objeto central de estudo em 14 artigos, seja na investigação de sua leitura (AGRELLO; GARG, 1999), em sua influência no aprendizado (OTERO; GRECA; SILVEIRA, 2003), na opinião dos professores sobre seu uso no ensino (FANARO; OTERO; GRECA, 2005), entre outros. Em um trabalho (AGUILAR; MATURANO; NÚNEEZ, 2007), a imagem foi utilizada como recurso para compreender outra questão: as concepções alternativas de estudantes.

Em relação ao campo de estudos de referência das pesquisas analisadas, aquelas que, explicitamente, posicionaram-se em relação a algum 
campo, o fizeram com a ciência cognitiva (OTERO; MOREIRA; GRECA; 2002; JIMÉNEZ VALLADARES; PERALES PALACIOS, 2002b) ou com a semiótica, juntamente com o a epistemologia (MEDEIROS; MEDEIROS, 2001).

Os artigos que analisaram os livros didáticos abordaram aspectos da produção da imagem (técnicas de produção de imagens, seus aspectos composicionais e as leituras esperadas dos estudantes). Todavia, nenhum deles se preocupou em analisar a leitura efetivamente realizada por professores e estudantes. $\mathrm{O}$ exame de livros didáticos universitários esteve presente em apenas um artigo.

Como instrumentos de coleta de dados, além da análise de livros didáticos, os autores empregaram testes para investigar o conhecimento dos estudantes acerca da disciplina e questionário que levantasse a opinião dos professores com relação ao uso da imagem no ensino. Ainda houve a realização de uma reflexão sobre o material produzido por estudantes (tirinhas) e utilizado em aula.

Ao proceder ao tratamento dos dados, os estudos utilizaram categorias originadas a partir do exame do material, com exceção de Medeiros e Medeiros (2001), que analisaram imagens de livros didáticos, tendo em vista a discussão epistemológica apresentada no artigo. Estes autores foram os únicos que apresentaram uma discussão sobre os paradigmas da ciência transmitidos por meio de imagens em livros didáticos. Sua reflexão teórica foi baseada nas diferenças entre os paradigmas aristotélicos (realismo ingênuo) e galileanos (realismo crítico) sobre as representações da realidade na ciência. A partir dessa reflexão, examinaram imagens presentes em três livros didáticos de Física que "incorrem em equívocos nos quais a representação do real concreto é confundida com a representação do real pensado na ciência” (MEDEIROS; MEDEIROS, 2001, p. 111).

Pudemos perceber, no artigo em que os professores foram sujeitos da pesquisa (FANARO; OTERO; GRECA, 2005), que suas ideias acerca dos benefícios do uso da imagem no ensino, geralmente, têm a ver com a aproximação dos conceitos científicos de situações cotidianas, diminuindo, assim, seu nível de abstração, o que pode indicar que, para eles, essas duas realidades (científica e cotidiana) são equivalentes, sugerindo uma igualdade entre os paradigmas aristotélicos e galileanos no que diz respeito à representação da realidade. 
Jiménez Valladares e Perales Palacios (2002a), sem mencionar, explicitamente, divergências entre paradigmas na ciência, demonstraram uma preocupação com a forma com que os livros didáticos de Física e Química tentam apresentar o conhecimento científico como uma representação exata da realidade concreta, por meio da utilização de imagens cotidianas. Sua análise de algumas imagens levou-os a concluir que sua intenção de apresentar conceitos teóricos (do mundo das ideias) como fatos experimentais (da realidade concreta) "pretende mostrar as 'verdades científicas' através de falsas situações experimentais [...] que reforçam uma visão empirista da atividade científica, claramente superada por uma nova filosofia da ciência” (JIMÉNEZ VALLADARES; PERALES PALACIOS, op. cit., p. 126; tradução nossa). ${ }^{4}$

Os referidos autores, em outro artigo (JIMÉNEZ VALLADARES; PERALES PALACIOS, 2002b), sugeriram investigações em atividades de ensino que tenham como referência as imagens. Embora não tenham exposto uma reflexão sobre mudanças de paradigmas na ciência, algumas de suas propostas poderiam ser usadas para tal finalidade, como a análise de formas de representação gráfica de livros didáticos antigos, a análise das imagens com diferentes graus de iconicidade, separando os planos realista e simbólico, e o uso de materiais concretos e suas diferenças com os símbolos utilizados para representá-los.

Assim, dos artigos analisados pelo presente trabalho, percebemos uma carência na discussão sobre os paradigmas da ciência transmitidos por meio de imagens em livros didáticos de Física. Pensamos ser essa uma reflexão importante, uma vez que trata da visão de mundo da ciência com que estudantes entram em contato em sua formação acadêmica e que, de alguma forma, influenciará sua atuação na vida.

\section{Considerações finais}

Admitindo-se que a produção e a leitura de imagens sejam influenciadas por nossa cultura, ou seja, por nossas vivências anteriores, temos a possibilidade de investigar aspectos da produção de imagens utilizadas nos livros didáticos de ciências, assim como sua leitura realizada por estudantes, com o intuito de perceber o modelo da ciência com o qual eles estão tendo contato em sua formação. Entretanto, o levantamento realizado nesse estudo aponta para uma carência de discussões em relação a esse tema. 
Sugerimos para futuras pesquisas uma análise das imagens, de suas relaçōes com o texto verbal, de leituras realizadas por estudantes em materiais didáticos e atividades de ensino que proporcionem um aprofundamento das questóes aqui apresentadas, tendo em vista uma aproximação com o paradigma vigente na ciência, seus contrapontos com paradigmas anteriores e as investigações que fizeram a comunidade científica substituir um paradigma por outro.

\section{Notas}

1. "Qualis é o conjunto de procedimentos utilizados pela Capes para estratificação da qualidade da produção intelectual de programas de pós-graduação" (http://www.qualis.capes.gov.br/ avaliacao/qualis. Acesso em: 6 nov. 2009).

2. "[...] desarrollar un instrumento de análisis de las secuencias didácticas de libros de texto de ciencias que posibilite, por un lado, determinar el papel que los autores atribuyen a las ilustraciones relativo a la metodología de enseñanza subyacente a cada libro" (JIMÉNEZ VALLADARES; PERALES PALACIOS, 2001, p. 4).

3. “[... la influencia que determinadas representaciones externas proporcionadas al sujeto, podrían tener en las representaciones mentales que construye para comprender un fenómeno físico” (OTERO; MOREIRA; GRECA, 2002, p. 128).

4. “[...] pretenden mostrar 'verdades científicas' mediante falsas situaciones experimentales [...] que refuerzan uma visión empirista de la actividad científica, algo claramente superado por la nueva Filosofía de la Ciencia” (JIMÉNEZ VALLADARES; PERALES PALACIOS, 2002a, p. 126).

\section{Referências}

AGRELLO, D.A; GARG, R. Compreensão de gráficos de cinemática em Física introdutória. Revista Brasileira de Ensino de Física, Porto Alegre, v. 21, n. 1, p. 103-115, mar. 1999. Disponível em: <http://www.sbfisica. org.br/rbef/ojs/index.php/rbef>. Acesso em: 5 jan. 2008.

AGUILAR, S.; MATURANO, C.; NÚNEZ, G. Utilización de imágenes para la detección de concepciones alternativas: un estudio exploratorio con estudiantes universitarios. Revista Electrónica de Enseñanza de las Ciencias, Barcelona, v. 6, n. 3, p. 691-713, 2007. Disponível em: <http://www.saum. uvigo.es/reec/>. Acesso em: 5 jan. 2008.

BRASIL. Ministério da Educação. Secretaria de Educação Básica (SEB). Guia de livros didáticos: PNLD 2012: Física. Brasília, DF: MEC/SEB, 2011.

Cad. Cedes, Campinas, v. 34, n. 92, p. 69-85, jan.-abr. 2014

Disponível em <http://www.cedes.unicamp.br> 
A imagem da ciência e as imagens visuais na formação superior...

COSTA, E.V.; ALMEIDA, L.C. Imagens tridimensionais: formação e análise. Revista Brasileira de Ensino de Física, São Paulo, v. 27, n. 2, p. 231-235, jun. 2005. Disponível em: <http://www.sbfisica.org.br/rbef/ojs/index.php/ rbef>. Acesso em: 5 jan. 2008.

DAVIES, J.; NERSESSIAN, N.J.; GOEL, A.K. Visual models in analogical problem solving. Foundations of Science, n. 10, p. 133-152, 2005. Disponível em: <http://web.ebscohost.com/ehost/>. Acesso em: 8 ago. 2009.

FANARO, M.A.; OTERO, M.R.; GRECA, I.M. Las imágenes en los materiales educativos: las ideas de los profesores. Revista Electrónica de Enseñanza de las Ciencias, Barcelona, v. 4, n. 2, p. 1-24, 2005. Disponível em: <http:// www.saum.uvigo.es/reec/>. Acesso em: 5 jan. 2008.

GALILI, I.; ZINN, B. Physics and art: a cultural symbiosis in physics education. Science \& Education, Dordrecht, v. 16, p. 441-460, 2007.

GONZÁLEZ-ESPADA, W.J. Integrating physical science and the graphic arts with scientifically accurate comic strips: rationale, description, and implementation. Revista Electrónica de Enseñanza de las Ciencias, Barcelona, v. 2, n. 1, p. 58-66, 2003. Disponível em: <http://www.saum.uvigo.es/ reec/>. Acesso em: 5 jan. 2008.

GOUVÊA, G.S.; OLIVEIRA, C.I.C. Imagens no livro didático: elementos de mediação em práticas de ensino. In: ENCONTRO NACIONAL DE DIDÁTICA E PRÁTICA DE ENSINO (ENDIPE), 15., 2010, Belo Horizonte. Anais.... Belo Horizonte: Endipe, 2010. (1 CD-ROM).

JIMÉNEZ VALLADARES, J.D.; PERALES PALACIOS, F.J. Aplicación del análisis secuencial al estudio del texto escrito e ilustraciones de los libros de física y química de la ESO. Enseñanza de las Ciencias, Barcelona, v. 19, n. 1, p. 3-19, mar. 2001.

JIMÉNEZ VALLADARES, J.D.; PERALES PALACIOS, F.J. La evidencia experimental a través de la imagen de los libros de texto de física y química. Revista Electrónica de Enseñanza de las Ciencias, Barcelona, v. 1, n. 2, p. 114-129, 2002a. Disponível em: <http://www.saum.uvigo.es/reec/>. Acesso em: 5 jan. 2008.

JIMÉNEZ VALLADARES, J.D.; PERALES PALACIOS, F.J. Las ilustraciones em la enseñanza-aprendizaje de las ciencias: análisis de libros de texto. Enseñanza de las Ciencias, Barcelona, v. 20, n. 3, p. 369-386, nov. 2002 b. 
KUHN, T.S. A estrutura das revoluções cientificas. 9. ed. São Paulo: Perspectiva, 2005.

MEDEIROS, A.; MEDEIROS, C. Questôes epistemológicas nas iconicidades de representações visuais em livros didáticos de Física. Revista Brasileira de Pesquisa em Educação em Ciências, Belo Horizonte, v. 1, n. 1, p. 103-117, jan./abr. 2001.

OTERO, M.R.; GRECA, I.M.; SILVEIRA, F.L. Imágenes visuales en el aula y rendimiento escolar en Física: un estudio comparativo. Revista Electrónica de Enseñanza de las Ciencias, Barcelona, v. 2, n. 1, p. 1-30, 2003. Disponível em: <http://www.saum.uvigo.es/reec/>. Acesso em: 5 jan. 2008.

OTERO, M.R.; MOREIRA, M.A.; GRECA, I.M. El uso de imágenes em textos de Física para la enseñanza secundaria y universitaria. Investigações em Ensino de Ciências, Porto Alegre, v. 7, n. 2, p. 127-154, maio/ago. 2002.

PEDUZZI, L.O.Q. Imagens complementares a um texto de Mecânica: a perspectiva de seu potencial para o aprendizado do aluno. Revista Brasileira de Ensino de Física, Porto Alegre, v. 21, n. 1, p. 136-151, mar. 1999. Disponível em: <http://www.sbfisica.org.br/rbef/ojs/index.php/rbef>. Acesso em: 5 jan. 2008.

REGO, S.C.R. Imagens fixas no ensino de Física: suas relaçōes com o texto verbal em materiais didáticos e padrões de leitura de licenciandos. Rio de Janeiro, 2011. Tese (Doutorado em Educação em Ciências e Saúde) - Núcleo de Tecnologia Educacional para a Saúde, Universidade Federal do Rio de Janeiro, Rio de Janeiro.

SILVA, H.C. Lendo imagens na educação científica: construção e realidade. Pro-Posições, Campinas, v. 17, n. 1, p. 71- 83, jan./abr. 2006.

Recebido em 12 de maio de 2013.

Aprovado em 11 de outubro de 2013. 